\title{
Variability and trends in corticosteroid use by male United States participants with Duchenne muscular dystrophy in the Duchenne Registry
}

\author{
Leslie Cowen ${ }^{1}$, Maria Mancini', Ann Martin², Ann Lucas ${ }^{2,3}$ and Joanne M. Donovan ${ }^{1 *}$
}

\begin{abstract}
Background: Treatment options for Duchenne muscular dystrophy remain limited, although consensus treatment guidelines recommend corticosteroid use.

Methods: This retrospective analysis assessed corticosteroid use in ambulatory and nonambulatory US males with Duchenne, age 35 and under, or Becker muscular dystrophy, who enrolled in The Duchenne Registry from 2007 to 2016 (formerly DuchenneConnect).

Results: The mean (SD) age of corticosteroid use initiation was 5.9 (2.5) years, and deflazacort use (54\%) was slightly more common than prednisone/prednisolone (46\%). Among all responses from those with Duchenne, $63 \%$ were currently on corticosteroids, $12 \%$ were no longer on corticosteroids, and $25 \%$ had never been on corticosteroids. Among those who were nonambulatory, 49\% were currently on corticosteroids, $28 \%$ had discontinued corticosteroids, and $23 \%$ had never used corticosteroids. Primary reasons for never initiating therapy were that corticosteroids were not prescribed or recommended and concerns about side effects. Corticosteroid use was maximal at age 8 (84\% on corticosteroids) and gradually declined from age 10 to 19 . The primary reasons for corticosteroid discontinuation were problems with side effects (65\%) or not enough benefit (28\%). Average doses of corticosteroids were below recommended doses. In the 159 responses with Becker muscular dystrophy, 20\% were currently using corticosteroids.
\end{abstract}

Conclusions: Recognizing the self-selected nature of participation, it appears that a considerable proportion of US participants registered with The Duchenne Registry were either not on corticosteroids or not on recommended doses despite consensus recommendations. Side effects were a consideration in initiating and discontinuing treatment. These data reinforce the need for additional treatment options for those affected by Duchenne.

Keywords: Duchenne muscular dystrophy, DuchenneConnect, The Duchenne Registry, Rare disease registries, Corticosteroids

\footnotetext{
* Correspondence: jdonovan@catabasis.com

${ }^{1}$ Catabasis Pharmaceuticals, One Kendall Square, Cambridge, MA 02139, USA

Full list of author information is available at the end of the article
}

(c) The Author(s). 2019 Open Access This article is distributed under the terms of the Creative Commons Attribution 4.0 International License (http://creativecommons.org/licenses/by/4.0/), which permits unrestricted use, distribution, and reproduction in any medium, provided you give appropriate credit to the original author(s) and the source, provide a link to the Creative Commons license, and indicate if changes were made. The Creative Commons Public Domain Dedication waiver (http://creativecommons.org/publicdomain/zero/1.0/) applies to the data made available in this article, unless otherwise stated. 


\section{Background}

Duchenne muscular dystrophy (Duchenne) is the most common genetic neuromuscular disease in children. Mutations in the X-linked dystrophin gene cause complete absence of dystrophin protein in skeletal, cardiac and respiratory muscle. In the absence of dystrophin, stress from repeated muscle contractions damages the sarcolemma and results in repeated cycles of inflammation, cellular degeneration and progressively failing muscle regeneration $[1,2]$. Birth prevalence is approximately 1 in 5000 newborn males [3]. Becker muscular dystrophy (Becker) is a milder dystrophy caused by partial absence of dystrophin and is less common than Duchenne with a later onset and slower course [4].

Although onset of Duchenne pathology can be observed in infancy [5], clinical symptoms typically manifest between 3 to 5 years of age with muscle weakness and wasting. Progressive lower limb muscle weakness results in loss of ambulation in adolescence, while respiratory muscle weakness leads to respiratory insufficiency requiring ventilation support beginning in late teens/early adulthood [6]. The use of ventilation support and glucocorticoids is associated with delayed loss of functional milestones and increase in life span [7] by several years from the previous median life expectancy of 19 years [8]. However, Duchenne is still associated with early mortality, most often from cardiac or respiratory failure, typically before 30 years of age [9].

Treatment options for Duchenne are limited. Eteplirsen (EXONDYS $51^{\circ}$ ) is an approved exon-skipping drug that targets exon 51 in the dystrophin gene and is appropriate for approximately $13 \%$ of patients with Duchenne [10]. Glucocorticoid therapy has been shown to have multiple benefits, including delaying loss of muscle function, loss of ambulation, onset of scoliosis, and respirator dependence, and improving strength and mobility [11-13]. A retrospective study of 97 patients with Duchenne reported improved functional outcomes with manageable adverse effects following 8.5 years of daily corticosteroid therapy [14]. A 10-year longitudinal study that followed males with Duchenne, with and without glucocorticoid therapy, reported that glucocorticoid treatment was associated with reduced risk of losing clinically meaningful mobility and upper limb disease progression milestones across the lifespan, as well as reduced risk of death [7]. However, long-term corticosteroid use can result in numerous side effects including growth inhibition, delay of puberty, weight gain, behavioral changes, long bone and vertebral fractures, Cushingoid facies and habitus, cataracts, and insulin resistance $[15,16]$, and current guidelines provide recommendations for management of side effects. Corticosteroid use long-term can also lead to myopathy through induction of several cellular pathways involving ubiquitin ligase (e.g., Murf1, atrogin1) and insulin-like growth factor I (IGF 1) [17, 18]. Thus, use of corticosteroids in patients with Duchenne requires diligent monitoring to ensure that both clinical benefits and side effect risks are managed appropriately [19]. The two most commonly prescribed corticosteroids in the US are prednisone and deflazacort [12], which was recently approved for Duchenne in the US $\left(\mathrm{EMFLAZA}^{\circ}\right)$ [20]. Deflazacort has been proposed to have fewer side effects than prednisone $[11,21,22]$. Evidence-based starting dose recommendations are 0.9 $\mathrm{mg} / \mathrm{kg} /$ day and $0.75 \mathrm{mg} / \mathrm{kg} /$ day (or $10 \mathrm{mg} / \mathrm{kg} /$ weekend) for deflazacort and prednisone, respectively, with dose reductions as necessary $[11,19]$. However, there is considerable variability in corticosteroid prescribing patterns for patients $[12,23,24]$. The purpose of this study was to understand the landscape of corticosteroid use in ambulatory and nonambulatory patients in the United States (US) with Duchenne or Becker muscular dystrophy.

\section{Methods}

Information entered by respondents enrolled in The Duchenne Registry was the primary data source. The Duchenne Registry, formerly known as DuchenneConnect, is a patient self-report registry and educational resource for individuals with Duchenne or Becker and carrier females [25]. The registry was established in 2007 by Parent Project Muscular Dystrophy and can be accessed at www.duchenneregistry.org. The majority (70\%) of enrolled participants are from the US. Participant data are curated by coordinators, and requests for updates to participant profiles occur every 6-12 months. Participants complete survey questionnaires on up to 12 topics, including diagnosis, mobility and musculoskeletal function, respiratory and cardiac function, and therapies including corticosteroid use. Because of the self-reported nature, not all questions were completed by all participants. As a result, the total number of responses varies for different questions. Data are maintained in a HIPAA-compliant database. All participants (patients 18 years and older or parents/ custodians/legal guardians of children under the age of 18) granted permission for de-identified information shared in the registry to be provided to researchers. Only The Duchenne Registry coordinators employed by Parent Project Muscular Dystrophy have access to identifying information. Participant permission was obtained via an electronic consent process at the time of registry account creation. The Duchenne Registry and electronic consent are approved by the Geisinger Institutional Review Board (Geisinger Medical Center, Danville, PA, IRB\#2014-0621).

The Duchenne Registry corticosteroid module captures information on current corticosteroid use patterns, reasons for discontinuing, and reasons for never initiating corticosteroids. Analysis of The Duchenne Registry 
database for information captured in the corticosteroid module was performed for US male Duchenne and Becker participants responding from October 2007 through November 2016. For participants with a diagnosis of Duchenne, only responses from males age 35 and under were included in the analysis. Selected analyses were also performed for males of any age diagnosed with Becker, and these are presented separately from the analyses for males with Duchenne.

Descriptive statistics (mean, standard deviation, median and range) were determined for participant responses. Age for steroid use refers to the age reported at the time the response was provided. If the respondent indicated that steroid use was unknown, they were not included in this analysis. For analysis by birth cohort, birth age was calculated from the age provided and the date the questionnaire was completed.

Respondents could submit additional responses at a later time point, although only a minority did (82 respondents completed the questionnaire two or three times for a total of 87 additional responses). Additional responses occurred an average of 2.7 years after the initial response, with a maximum of 9 years later. If an individual submitted two responses that captured one-time past events such as age of initiation of steroids, only the most recent response was used in analyses. For module questions regarding current corticosteroid steroid use, responses collected at different ages were included since they provided additional information on use of steroids at different ages.

\section{Results}

\section{Participants}

As of December 31, 2016, The Duchenne Registry had 3791 total registrants, and there were 3560 responses in which a diagnosis was reported. Of these, 3311/3560 (93.0\%) were analyzed, 3005/3560 (84.4\%) were responses for a diagnosis of Duchenne, and 306/3560 (8.6\%) were for a diagnosis of Becker. As shown in Fig. 1, among 3311 responses from only males with a diagnosis of Duchenne or Becker, there were 2601 responses to the corticosteroid module, and 1816 of these responses were for US participants. After excluding responses from US males diagnosed with Duchenne who were over the age of $35(n=30)$, there were 1627 responses from 1538 individuals, and 159 responses from 154 individuals of any age diagnosed with Becker.

Table 1 shows the characteristics of the US males age 35 or under with Duchenne and US males with Becker who provided data in the corticosteroid module. Among males with Duchenne, mean age (SD) was 11.3 (6.5) years, the majority $(88.9 \%)$ were less than 20 years old and Caucasian (87.2\%), and most individuals were ambulatory $(59.3 \%)$, with $40.0 \%$ nonambulatory. The mean age (SD) of onset for full-time use of a scooter/wheelchair was 10.8 (2.5) years. Among males with Becker, the mean age (SD) was 21.8 (16.2) years and the age distribution was broad. The majority were Caucasian (89.7\%) and most individuals were ambulatory $(76.4 \%)$.

\section{Corticosteroid use patterns}

The use of corticosteroids for males with Duchenne or Becker is shown in Table 2. Among those with Duchenne, $63.0 \%$ (969/1538) reported the current use of steroids, with deflazacort use slightly greater than prednisone/prednisolone use $(54.1 \%$ vs $45.9 \%$ of those currently using corticosteroids, respectively). Twenty-five percent (381/1538) of males with Duchenne had never used corticosteroids and $12.2 \%(188 / 1538)$ had a previous history of using corticosteroids, but were no longer using them. Among 569 nonambulatory males with Duchenne, 23.0\% (131/569) had never been on steroid therapy, 48.7\% (277/569) were currently using corticosteroids, and 28.3\% (161/569) had previously used corticosteroids. Deflazacort and prednisone/prednisolone use among nonambulatory males was similar to use in the overall Duchenne group ( $47.7 \%$ vs $52.3 \%$, respectively).

Among 154 males with Becker, 19.5\% (30/154) currently used corticosteroids, mostly deflazacort, $5.8 \%$ (9/154) were no longer using corticosteroids, and 74.6\% $(115 / 154)$ had never used corticosteroids.

Unique responses for age at corticosteroid initiation were provided by 651 males with Duchenne that had ever used steroids. The age distribution at initiation of treatment is shown in Fig. 2. The modal age for treatment initiation was 5 years, with a mean (SD) of 5.9 (2.5) years. Almost all of those who were ever treated with corticosteroids $(637 / 651,97.8 \%)$ initiated treatment before 12 years of age.

For males with Duchenne, treatment status by age is shown in Fig. 3. The highest use of corticosteroids was between 8 and 12 years of age, where at least $76.3 \%$ of males at any age were on therapy. After age 9 , more than $10 \%$ had discontinued corticosteroid treatment in each age group.

Corticosteroid use by age for ambulatory and nonambulatory males with Duchenne is shown in Fig. 4a and b, respectively. The majority of ambulatory participants age 10 or under $(67 \%)$ and over the age of $10(89 \%)$, were using corticosteroid therapy. In contrast, among nonambulatory patients $\leq$ or $>10$ years of age, 49 and $52 \%$, respectively, were using corticosteroid therapy.

\section{Corticosteroid dose}

The average doses of prednisone/prednisolone and deflazacort reported by participants overall were 0.5 and 0.6 $\mathrm{mg} / \mathrm{kg}$, respectively, corresponding to $67 \%$ of the starting doses $(0.75$ and $0.9 \mathrm{mg} / \mathrm{kg}$, respectively) recommended 


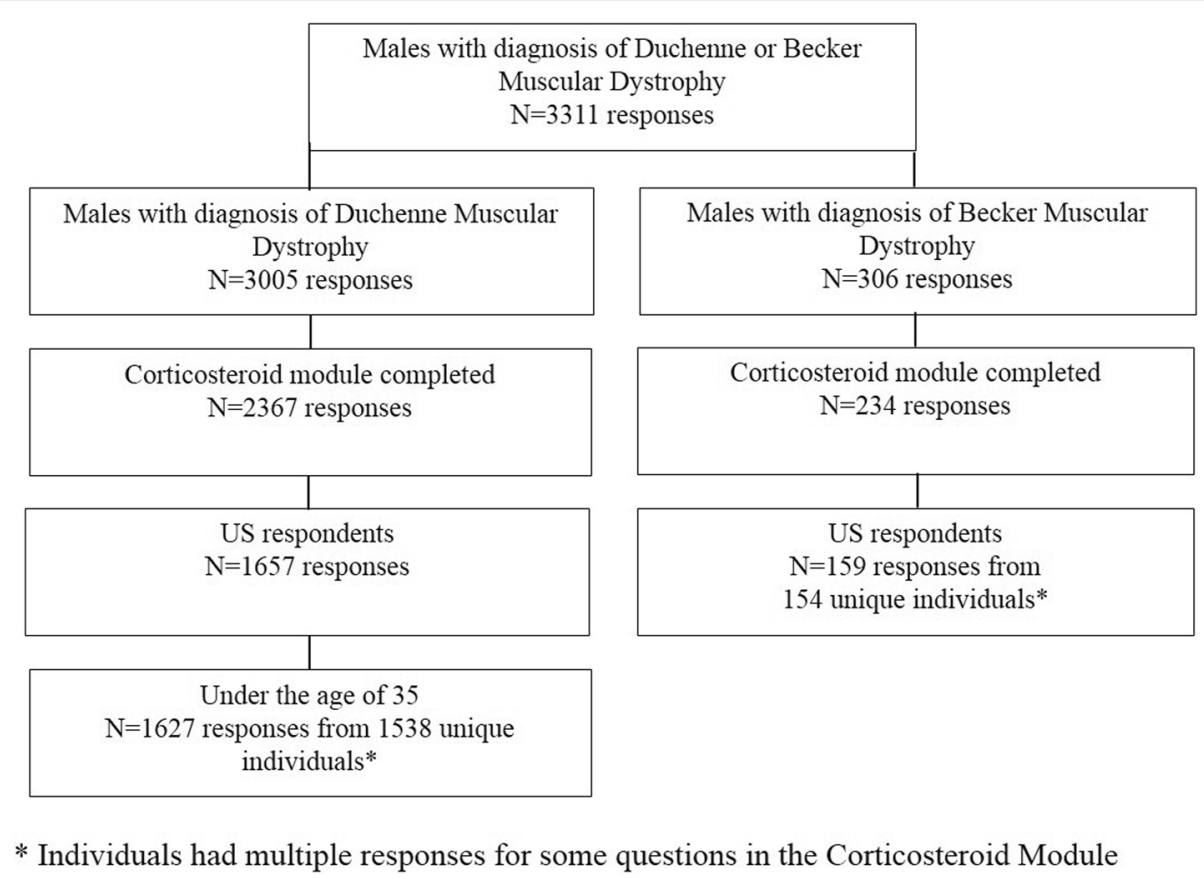

Fig. 1 Flow Diagram for Responses in The Duchenne Registry Study for Participants with Duchenne or Becker Muscular Dystrophy

in current guidelines [19]. Average doses by participant age are shown in Fig. 5. Average doses of deflazacort tended to be higher at younger ages and declined with age.

\section{Corticosteroid history}

Among 1246 males with Duchenne currently on corticosteroid therapy, 377 (29.7\%) provided details on their history of corticosteroid use. The majority, 92.0\% (347/ 377), had taken corticosteroids continuously and 7.9\% $(30 / 377)$ had taken at least one break from steroid use. As shown in Table 3, among the 46 males who discontinued corticosteroid therapy and provided reasons for discontinuation, the primary reported reason for discontinuation was problems with side effects (30/46, 65.2\%), including known side effects such as weight gain, behavioral changes, osteoporosis and fractures, followed by not enough benefit (13/46, 28.3\%). Among the 47 males who discontinued corticosteroid therapy, 59.6\% (28/47) responded that they would not consider resuming corticosteroids even if there was new information about the long-term benefits of using corticosteroids, while $40.4 \%$ $(19 / 47)$ responded they would consider resuming corticosteroids.

One hundred fourteen males with Duchenne who had never initiated corticosteroid therapy responded with the reasons for not starting treatment shown in Table 3. The primary reasons reported were concern over side effects (25.4\%) and that corticosteroids were never prescribed/ recommended (22.8\%), with $27.2 \%$ being age 3 or under.

\section{Corticosteroid use by time period}

Steroid use for different birth cohorts is shown in Table 4. Age at initiation of steroids has steadily declined over time, while the use of corticosteroids increased, and the discontinuation rate has generally fallen. Since the most recent cohort (birth years 2005 to 2009) lacks full information for age 7 and up, comparison was made for the 4 to 7 -year old age range. The frequency of corticosteroid use was similar for the birth cohort 2000-04 and 2005-09.

\section{Discussion}

Glucocorticoid therapy is considered the standard of care for Duchenne [11], although variations in prescribing practices indicate uncertainty regarding when treatment should be initiated, the risk/benefit assessment of long-term therapy, dosing regimens, and when treatment should stop [24]. A recent Cochrane review of published studies concluded from randomized clinical trials that corticosteroid therapy improves strength and function with acceptable tolerability up to 6 months [26]. Deflazacort and prednisone treatment for 12 weeks at the recommended doses of $0.9 \mathrm{mg} / \mathrm{kg} /$ day and $0.75 \mathrm{mg} / \mathrm{kg} /$ day, respectively, demonstrated similar benefits in muscle strength and similar adverse effect profiles (including Cushingoid appearance, increased weight, erythema, and hirsutism) compared to placebo [21], with the limitation that conclusions on long-term corticosteroid treatment are drawn from non-randomized studies [26]. A retrospective study of 97 patients with Duchenne reported 
Table 1 Characteristics of Duchenne Registry Respondents (Males with Duchenne and $\leq 35$ years old) who completed the Corticosteroid Module)

\begin{tabular}{|c|c|c|}
\hline \multirow[t]{2}{*}{ Characteristic } & \multicolumn{2}{|c|}{ Number of Responses and Number of Patients } \\
\hline & 1627 from 1538 males with Duchenne & 159 from 154 males with Becker \\
\hline \multicolumn{3}{|l|}{ Age (years) } \\
\hline Mean (SD) & $11.3(6.5)$ & $21.8(16.2)$ \\
\hline Median (1st quartile, 3rd quartile) & $10(7,15)$ & $17(9,34)$ \\
\hline \multicolumn{3}{|l|}{ Age Category n, (\%) } \\
\hline$\leq 4$ years old & $200(12.3)$ & $8(5.1)$ \\
\hline 5-9 years old & $544(33.4)$ & $35(22.3)$ \\
\hline 10-14 years old & $470(28.9)$ & $24(15.3)$ \\
\hline 15-20 years old & $232(14.3)$ & $19(12.1)$ \\
\hline $21-24$ years old & $99(6.1)$ & $15(9.6)$ \\
\hline 25-29years old & $54(3.3)$ & $9(5.7)$ \\
\hline 30-35 years old & $28(1.7)$ & $11(7.0)$ \\
\hline$>35$ years old & NA & $33(21.0)$ \\
\hline \multicolumn{3}{|l|}{ Race $n,(\%)$} \\
\hline Caucasian & $1406(87.2)$ & $140(89.7)$ \\
\hline Asian & $83(5.1)$ & $6(3.8)$ \\
\hline Other & $72(4.5)$ & $5(3.2)$ \\
\hline Black & $29(1.8)$ & $3(1.9)$ \\
\hline Native American & $18(1.1)$ & $2(1.3)$ \\
\hline Pacific Islander & $4(<1)$ & 0 \\
\hline \multicolumn{3}{|l|}{ Ethnicity $n,(\%)$} \\
\hline Not Latino/Hispanic & $1392(90.2)$ & 143 \\
\hline Latino/Hispanic & $152(9.8)$ & 7 \\
\hline Ambulatory Status $n,(\%)$ & $N=1505$ & $N=140$ \\
\hline Child is an infant/toddler and has not yet taken his/her first steps & $11(0.7)$ & 0 \\
\hline Ambulatory & $892(59.3)$ & $107(76.4)$ \\
\hline Usually/always walk without help or mobility devices & $645(42.9)$ & $90(64.3)$ \\
\hline Sometimes need help from a mobility device & $247(16.4)$ & $17(12.1)$ \\
\hline \multicolumn{3}{|l|}{ Nonambulatory } \\
\hline Use a wheelchair/other mobility device and rarely/ never walk & $602(40.0)$ & $33(23.6)$ \\
\hline
\end{tabular}

Table 2 Corticosteroid Use and Status in US Males with Duchenne Muscular Dystrophy under the Age of 35, and US Males with Becker Muscular Dystrophy Enrolled in The Duchenne Registry

\begin{tabular}{|c|c|c|c|c|}
\hline \multirow[b]{2}{*}{ Population } & \multicolumn{3}{|l|}{ Duchenne } & \multirow{2}{*}{$\begin{array}{l}\text { Becker } \\
\text { All }\end{array}$} \\
\hline & $\overline{\text { All }}$ & Ambulatory $^{\mathrm{b}}$ & Nonambulatory $^{b}$ & \\
\hline Males with Duchenne Muscular Dystrophy $n,(\%)$ & $N=1538$ & $N=845$ & $N=569$ & $N=154$ \\
\hline Currently using corticosteroids & $969(63.0)$ & $604(71.5)$ & $277(48.7)$ & $30(19.5)$ \\
\hline Deflazacort ${ }^{\mathrm{a}}$ & $524(54.1)^{a}$ & $344(57.0)^{a}$ & $132(47.7)^{a}$ & $21(70.0)^{\mathrm{a}}$ \\
\hline Prednisone/prednisolone $e^{a}$ & $445(45.9)^{\mathrm{a}}$ & $260(43.0)^{a}$ & $145(52.3)^{a}$ & $9(30.0)^{\mathrm{a}}$ \\
\hline Never used corticosteroids & $381(24.8)$ & $223(26.3)$ & $131(23.0)$ & $115(74.6)$ \\
\hline Used to take corticosteroids & $188(12.2)$ & $18(2.1)$ & $161(28.3)$ & $9(5.8)$ \\
\hline
\end{tabular}

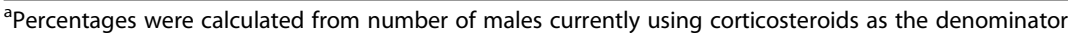

${ }^{\mathrm{b}}$ Not all respondents provided ambulatory status 


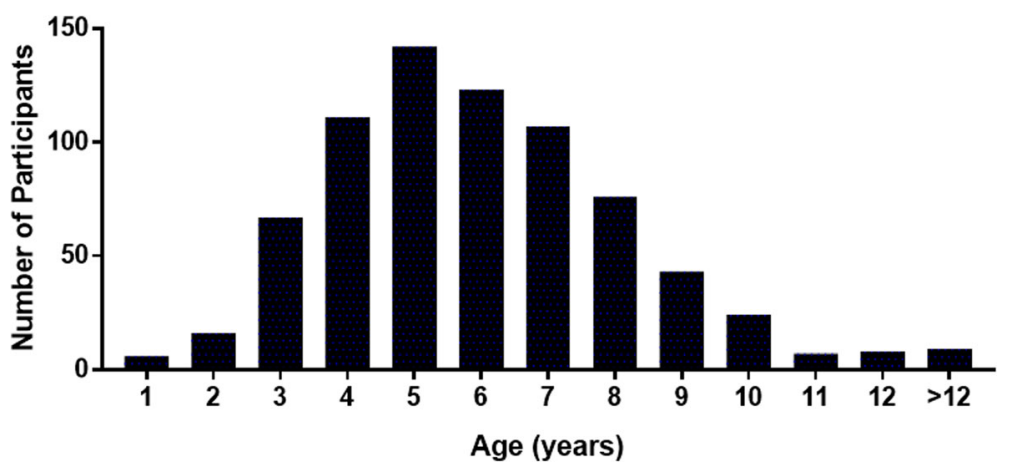

Fig. 2 Age Distribution at Initiation of Corticosteroid therapy for Males with Duchenne Muscular Dystrophy. Unique responses for age at corticosteroid initiation were provided by 651 males with Duchenne that had ever used steroids

improved functional outcomes with manageable adverse effects following 8.5 years of daily corticosteroid therapy [14]. Nonetheless, management of the patient with long-term corticosteroid therapy while minimizing side effects is challenging [27]. An ongoing clinical trial in five countries will attempt to standardize corticosteroid dosing and management for patients with Duchenne [23].

Analysis of corticosteroid use by US patients registered with The Duchenne Registry reaffirms the uncertainties surrounding corticosteroid treatment regimens. Almost $25 \%$ of participants with Duchenne from ages 4 to 35 had never used corticosteroids, even though the American Academy of Neurology recommends corticosteroids for improving strength and pulmonary function [11]. The primary reasons for not using corticosteroids were that they were not prescribed/recommended, as well as concerns over side effects. It should be noted that older patients in the registry were managed prior to the time when treatment guidelines strongly recommended steroid use; however, the majority $(75 \%)$ of participating registrants were younger than 15 years of age.

Among participants with Becker, a considerable minority (25.3\%) had used corticosteroids. Although there are case reports suggesting that some patients with Becker may benefit from corticosteroid therapy [28, 29], risks of long-term corticosteroid use must be weighed against uncertainties of benefit in this population. It is also possible that some patients diagnosed with Becker that were prescribed corticosteroids may have been thought to have Duchenne or intermediate dystrophinopathy.

Corticosteroid use was highest in participants with Duchenne between the ages of 6 and 12, with a modal age at initiation of corticosteroid use of 5 years. Guidelines on when glucocorticoid therapy should be initiated in ambulatory patients with Duchenne recommend initiation prior to substantial decline in mobility [19]. For US registrants that were ambulatory, corticosteroid use peaked at age 8 years. Decisions on when to initiate corticosteroid therapy are typically based on an individual's age, functional state, and pre-existing risk factors for potential corticosteroid adverse effects. In contrast, corticosteroid use in younger participants between 4 and 8 years of age did not increase notably. These data reinforce that there are concerns/uncertainty among patients and prescribers regarding side effects and efficacy.

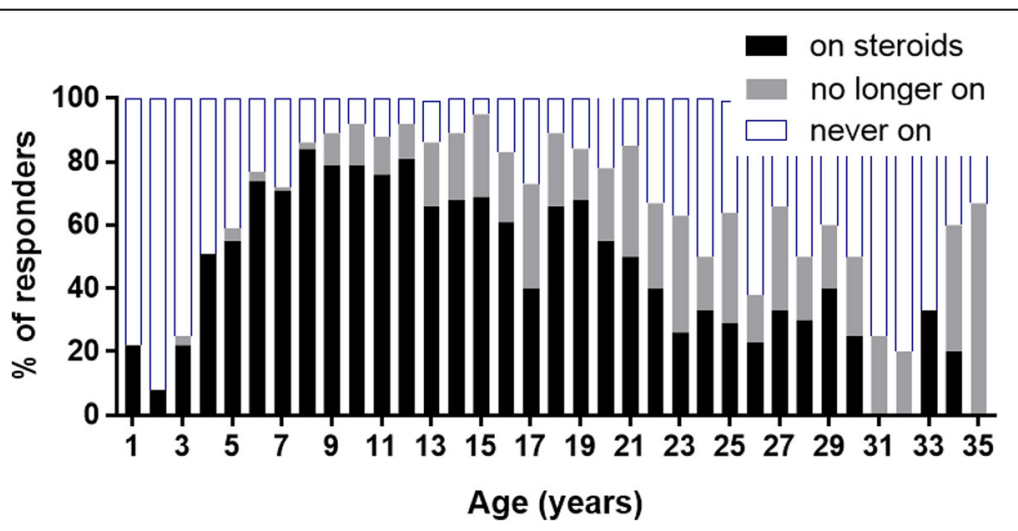

Fig. 3 Corticosteroid Treatment Status for Males with Duchenne Muscular Dystrophy. The percentages of males with Duchenne receiving corticosteroid therapy, no longer receiving therapy, or never on corticosteroids are shown stratified by patient age 


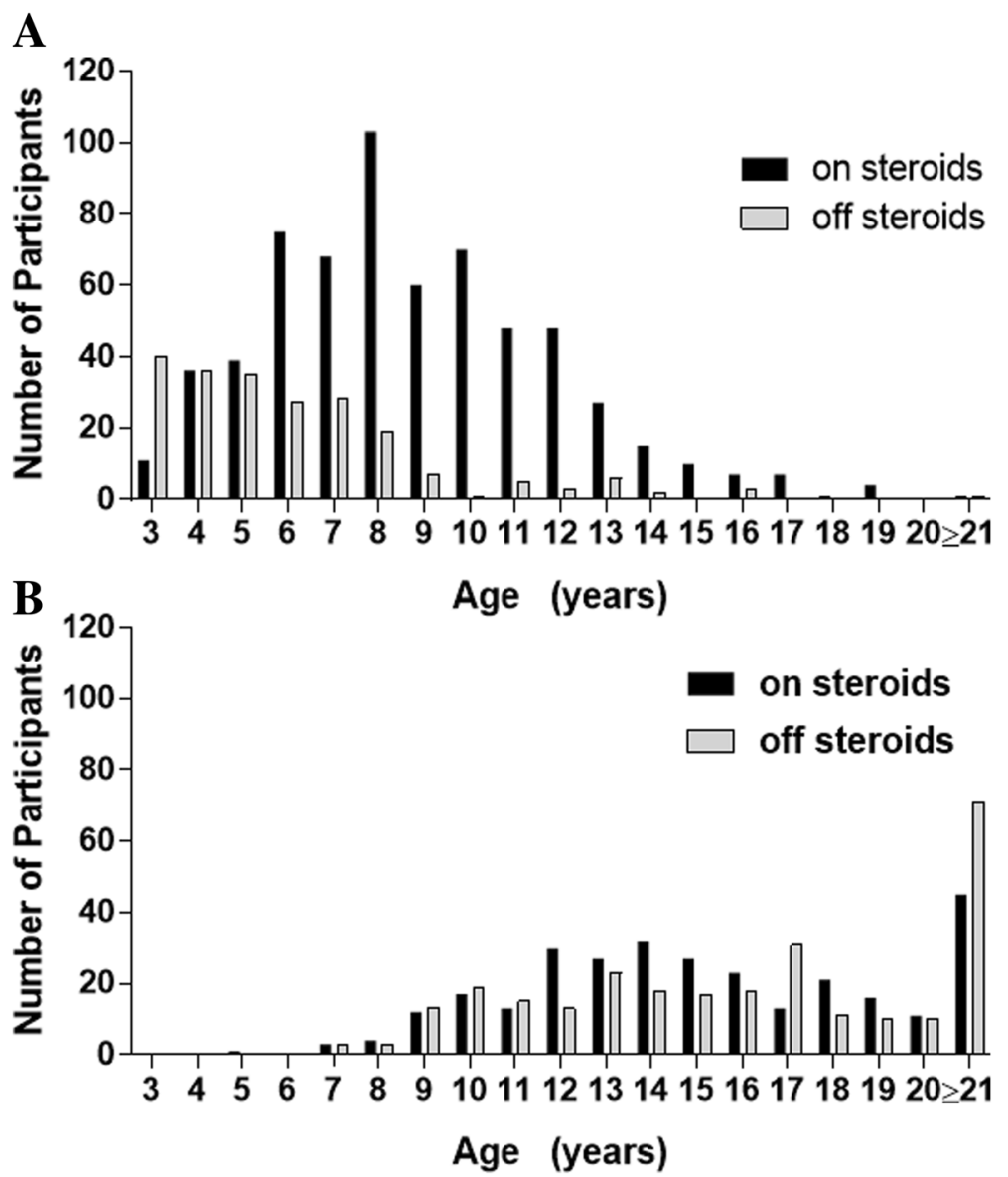

Fig. 4 Corticosteroid Status for Males with Duchenne Muscular Dystrophy Stratified by Age. Numbers of ambulatory (a) and nonambulatory (b) patients treated with corticosteroids and not treated with corticosteroids are shown by patient age

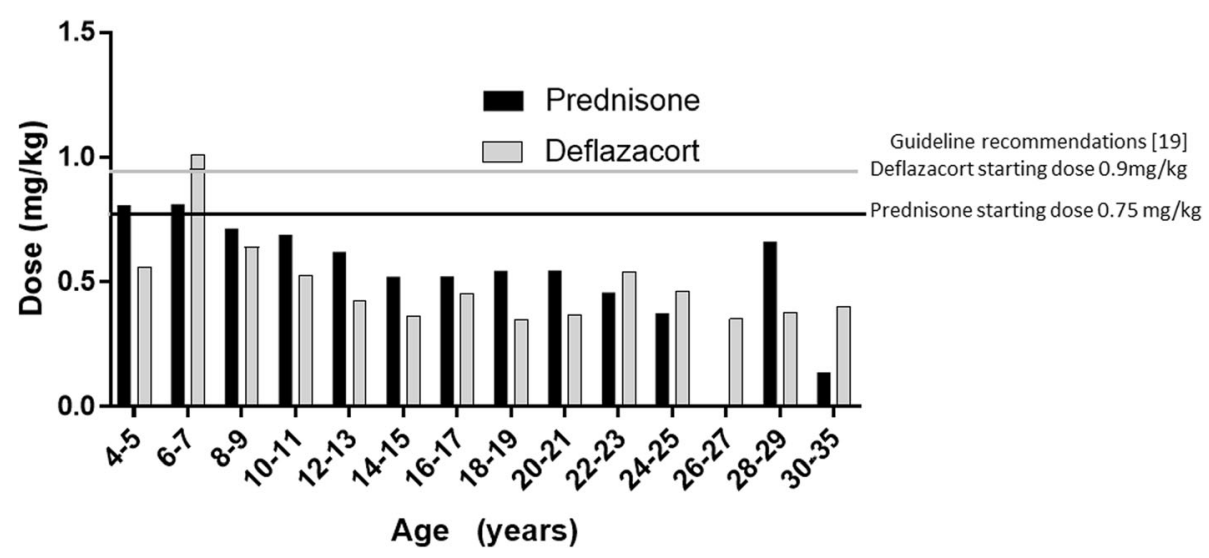

Fig. 5 Average Corticosteroid Dose Stratified by Age Group for Males with Duchenne Muscular Dystrophy. Mean reported dose of prednisone or deflazacort used by males with Duchenne is shown for each age group. Horizontal lines indicate recommended prednisone (black line) and deflazacort (grey line) starting doses [19] 
Table 3 Primary Reasons for Discontinuing or not Initiating Corticosteroid Therapy among Males with Duchenne Muscular Dystrophy

\begin{tabular}{ll}
\hline Module Query & Number (\%) \\
\hline Reasons for Discontinuing Corticosteroid Therapy $n(\%)$ & $N=46$ \\
Problems with side effects & $30(65.2)$ \\
Not enough benefits & $13(28.3)$ \\
Did not like the use of long term medication & $2(4.3)$ \\
Other & $1(2.2)$ \\
Reasons for not Initiating Corticosteroid Therapy $n \%$ & $N=114$ \\
Worried about side effects & $29(25.4)$ \\
Doctor never prescribed/recommended & $26(22.8)$ \\
Other (starting soon, too young most common) & $20(17.5)$ \\
Worried about not getting enough benefits & $7(6.1)$ \\
Does not like the use of long term medicine & $1(0.9)$ \\
Age 3 or under & $31(27.2)$ \\
\hline
\end{tabular}

${ }^{\mathrm{a}} \mathrm{A}$ minority of respondents answered these questions

After the age of 9 , at least $10 \%$ of respondents had discontinued steroids. The primary reasons reported for discontinuation included problems with side effects and not enough benefit. For participants who discontinued corticosteroid therapy, the majority of participants would not consider resuming corticosteroids even if there was new information about long-term benefits. While the reason for not considering resuming corticosteroids was not captured, problems with side effects are likely contributing factors. Discontinuations may also reflect the uncertainty surrounding both long-term use of corticosteroids and whether corticosteroid therapy should be maintained once ambulation decreases. Mean age at loss of ambulation for participants with Duchenne was between 10 and 11 years of age. Corticosteroid use was highest among nonambulatory participants between the ages of 12 and 18 . While the case is made for continuation of glucocorticoids after loss of ambulation in order to preserve upper limb strength and respiratory function and reduce the need for spinal surgery due to scoliosis [30,31], the risk/benefit for individual patients is a consideration.
Deflazacort use was slightly greater than use of prednisone/prednisolone, which is notable since deflazacort was not approved in the US for use in Duchenne until after these data were collected [20]. The substantial use of deflazacort may reflect a selection bias in that parents/patients that are registry participants are likely to be better informed and were more likely to be able to request and obtain deflazacort, given published evidence that deflazacort may be associated with greater preservation of muscle function [22]. Clinical trials also indicate that deflazacort may result in less weight gain than prednisone but is associated with decreased stature and more asymptomatic cataracts $[11,21]$. A randomized controlled trial assessing corticosteroid therapy for Duchenne is ongoing [23].

In 2016, the American Academy of Neurology (AAN) recommended a starting dose of prednisone at $0.75 \mathrm{mg} /$ $\mathrm{kg} /$ day (or $10 \mathrm{mg} / \mathrm{kg} /$ weekend) [11] and the approved label dose of deflazacort is $0.9 \mathrm{mg} / \mathrm{kg} /$ day [20]. Interestingly, the doses of prednisone and deflazacort reported by participants in The Duchenne Registry varied considerably by age (with trends for decreases in older patients), and the average doses were $67 \%$ of the recommended doses. These results are similar to results reported in a Duchenne natural history study where average doses of prednisone/ prednisolone and deflazacort where 75 and $83 \%$, respectively, of the recommended doses [12]. It is important to note that The Duchenne Registry does not capture specific doses of corticosteroids prescribed by practitioners, but rather the reported actual dose, which may account for some of the variability.

Patient and family participation in The Duchenne Registry is extremely valuable in order to further clinical development of new treatments for Duchenne. The Duchenne Registry is the largest US-based patient report registry and can provide important natural history data that can inform practitioners and researchers regarding trends in patient care and reasons why patients and families make treatment decisions. Inherent limitations to registry-based data analysis include that entries are based on patient/caregiver reporting and may have

Table 4 Corticosteroid Use by Birth Year for Males with Duchenne Muscular Dystrophy

\begin{tabular}{|c|c|c|c|c|c|c|c|}
\hline Birth Interval (years) & $\begin{array}{l}\text { Age at initiation of steroids } \\
\text { (years, median, 1st and 3rd quartiles) }^{\mathrm{a}}\end{array}$ & $\mathrm{N}$ & On steroids $\%, n$ & Discontinued $\%, n$ & Never on steroids $\%, n$ & $\begin{array}{l}\text { Age } 4 \mathrm{t} \\
\text { steroids }\end{array}$ & 7 not on \\
\hline $1980-89$ & $9(7,17)$ & 87 & $20.7 \% 18$ & $31.0 \% 27$ & $48.3 \% 42$ & NA & NA \\
\hline 1990-94 & $8(6,10)$ & 138 & $42.8 \% 59$ & $29.7 \% 41$ & $27.5 \% 38$ & NA & NA \\
\hline 1995-99 & $7(6,8)$ & 316 & $66.5 \% 210$ & $21.2 \% 67$ & $12.3 \% 39$ & NA & NA \\
\hline $2000-04$ & $6(4,8)$ & 449 & $77.7 \% 349$ & $10.5 \% 47$ & $11.8 \% 53$ & $67.6 \%$ & $46 / 68$ \\
\hline $2005-09^{c}$ & $5(4,6)$ & 418 & $75.6 \% 316$ & $3.3 \% 14$ & $21.1 \% 88$ & $69.6 \%$ & $156 / 224$ \\
\hline
\end{tabular}

${ }^{a}$ For those who provided age at initiation (overall $60.2 \%, 692 / 1148$ )

bOnly available for cohorts in which there were registrants in this age range (i.e., after birth year 2000)

${ }^{C}$ Youngest members of this cohort were 7 years of age

$N A=$ not available 
missing or inconsistent data which may confound results. The Duchenne Registry participants represent approximately $14 \%$ of individuals with Duchenne in the US, and systematic biases among participants prevents generalization of findings to all patients. In addition, The Duchenne Registry registrants likely represent a cohort of well-informed and motivated patients. However, the results on corticosteroid use patterns are consistent with population-based studies of corticosteroid use in males with Duchenne [32, 33]. In a retrospective study comparing males born 1982 to 1986 with males born 1997 to 2001 , steroid use increased by $20 \%$ and mean age at steroid initiation decreased by year [32]. An international, center-based longitudinal study begun in 2006 assessed glucocorticoid treatment status for males with Duchenne and found that, among 340 males between the ages of 2 and $28,62 \%$ were on corticosteroid therapy, $14 \%$ were no longer on therapy, and $24 \%$ had never been on therapy [33] at baseline. Our results in a registry US population five times the size of the 2006 study demonstrated almost identical percentages of males who were on therapy (62\%), had a history of therapy $(12 \%)$, and who were therapy naïve (24\%).

\section{Conclusions}

Glucocorticoids have a range of adverse side effects that influence patient initiation and continuation with therapy, and a considerable proportion of patients with Duchenne registered with The Duchenne Registry in the US are not on recommended glucocorticoid therapy. Analysis of The Duchenne Registry data reinforces the need for safe and effective treatment options for those affected by Duchenne.

\section{Abbreviations}

AAN: American Academy of Neurology; HIPAA: Health Insurance Portability and Accountability Act; IGF 1: insulin-like growth factor type 1; Murf1: muscle ring-finger protein-1 gene, a ubiquitin ligase; SD: standard deviation; US: United States

\section{Acknowledgments}

The authors thank the patients and families providing data in The Duchenne Registry. Patrice Ferriola, PhD, provided medical writing and editing assistance in preparation of the manuscript.

\section{Funding}

Parent Project Muscular Dystrophy maintains and supports The Duchenne Registry. Catabasis Pharmaceuticals provided funding for analysis of The Duchenne Registry data and provided support for medical writing provided by Patrice Ferriola of KZE PharmAssociates.

\section{Availability of data and materials}

The datasets analysed during the current study are available in the Duchenne Registry, [https://www.duchenneregistry.org/]. All Duchenne Registry data have also been shared with C-PATH and the Duchenne Regulatory Science Consortium.

\section{Authors' contributions}

LC, MM and JD designed the study and analyzed data; AM and AL collected and analyzed data; all authors developed manuscript drafts. All authors read and approved the final manuscript.

\section{Ethics approval and consent to participate}

Written informed consent from participants or their parents/guardians was obtained in compliance with all local laws and regulations, and institutional investigational review board or ethics committee approval. The Duchenne Registry and electronic consent are approved by the Geisinger Institutional Review Board (Geisinger Medical Center, Danville, PA, IRB\#2014-0621).

\section{Consent for publication}

Not applicable.

\section{Competing interests}

LC, MM and JD are employees of Catabasis Pharmaceuticals, the study sponsor, which is developing an investigational drug, edasalonexent, for treatment of Duchenne muscular dystrophy, which is being studied in patients not on corticosteroids.

\section{Publisher's Note}

Springer Nature remains neutral with regard to jurisdictional claims in published maps and institutional affiliations.

\section{Author details}

${ }^{1}$ Catabasis Pharmaceuticals, One Kendall Square, Cambridge, MA 02139, USA. ${ }^{2}$ Parent Project Muscular Dystrophy, Hackensack, NJ, USA. ${ }^{3}$ Present address: Sanofi Genzyme, Cambridge, MA, USA.

Received: 10 December 2018 Accepted: 15 April 2019

Published online: 02 May 2019

References

1. Emery AE. The muscular dystrophies. Lancet. 2002;359:687-95.

2. Blake DJ, Weir A, Newey SE, Davies KE. Function and genetics of dystrophin and dystrophin-related proteins in muscle. Physiol Rev. 2002;82:291-329.

3. Ryder S, Leadley RM, Armstrong N, Westwood M, de Kock S, Butt T, et al. The burden, epidemiology, costs and treatment for Duchenne muscular dystrophy: an evidence review. Orphanet J Rare Dis. 2017;12:79.

4. Flanigan KM. Duchenne and Becker muscular dystrophies. Neurol Clin. 2014:32:671-88 viii.

5. Chen YW, Nagaraju K, Bakay M, Mclntyre O, Rawat R, Shi R, et al. Early onset of inflammation and later involvement of TGFbeta in Duchenne muscular dystrophy. Neurology. 2005;65:826-34.

6. McDonald CM, Mercuri E. Evidence-based care in Duchenne muscular dystrophy. Lancet Neurol. 2018;17:389-91.

7. McDonald CM, Henricson EK, Abresch RT, Duong T, Joyce NC, Hu F, et al. Long-term effects of glucocorticoids on function, quality of life, and survival in patients with Duchenne muscular dystrophy: a prospective cohort study. Lancet. 2018;391:451-61.

8. Kohler M, Clarenbach CF, Bahler C, Brack T, Russi EW, Bloch KE. Disability and survival in Duchenne muscular dystrophy. J Neurol Neurosurg Psychiatry. 2009;80:320-5.

9. Kieny $P$, Chollet $S$, Delalande $P$, Le Fort M, Magot A, Pereon $Y$, et al. Evolution of life expectancy of patients with Duchenne muscular dystrophy at AFM Yolaine de Kepper Centre between 1981 and 2011. Ann Phys Rehabil Med. 2013;56:443-54

10. Mendell JR, Goemans N, Lowes LP, Alfano LN, Berry K, Shao J, et al. Longitudinal effect of eteplirsen versus historical control on ambulation in Duchenne muscular dystrophy. Ann Neurol. 2016;79:257-71.

11. Gloss D, Moxley RT, 3rd, Ashwal S, and Oskoui M. Practice guideline update summary: corticosteroid treatment of Duchenne muscular dystrophy: report of the guideline development Subcommittee of the American Academy of neurology. Neurology 2016;86:465-472.

12. Bello L, Gordish-Dressman H, Morgenroth LP, Henricson EK, Duong T, Hoffman EP, et al. Prednisone/prednisolone and deflazacort regimens in the CINRG Duchenne natural history study. Neurology. 2015;85:1048-55.

13. Henricson EK, Abresch RT, Cnaan A, Hu F, Duong T, Arrieta A, et al. The cooperative international neuromuscular research group Duchenne natural history study: glucocorticoid treatment preserves clinically meaningful functional milestones and reduces rate of disease progression as measured by manual muscle testing and other commonly used clinical trial outcome measures. Muscle Nerve. 2013;48:55-67.

14. Wong BL, Rybalsky I, Shellenbarger KC, Tian C, McMahon MA, Rutter MM, et al. Long-term outcome of interdisciplinary Management of Patients with 
Duchenne muscular dystrophy receiving daily glucocorticoid treatment. J Pediatr. 2017;182:296-303.e1.

15. Bushby K, Finkel R, Birnkrant DJ, Case LE, Clemens PR, Cripe L, et al. Diagnosis and management of Duchenne muscular dystrophy, part 1: diagnosis, and pharmacological and psychosocial management. Lancet Neurol. 2010;9:77-93.

16. Ward LM, Kinnett K, Bonewald L. Proceedings of a Parent Project Muscular Dystrophy bone health workshop: morbidity due to osteoporosis in DMD: the Path forward may 12-13, 2016, Bethesda, Maryland, USA. Neuromuscul Disord. 2018;28:64-76.

17. Hanaoka BY, Peterson CA, Horbinski C, Crofford LJ. Implications of glucocorticoid therapy in idiopathic inflammatory myopathies. Nat Rev Rheumatol. 2012;8:448-57.

18. Schakman O, Gilson H, Kalista S, Thissen J. Mechanisms of muscle atrophy induced by glucocorticoids. Hormone Res. 72(Suppl 1):36-41.

19. Birnkrant DJ, Bushby K, Bann CM, Apkon SD, Blackwell A, Brumbaugh D, et al. Diagnosis and management of Duchenne muscular dystrophy, part 1: diagnosis, and neuromuscular, rehabilitation, endocrine, and gastrointestinal and nutritional management. Lancet Neurol. 2018;17:251-67.

20. Voelker R. First corticosteroid approved for Duchenne muscular dystrophy. Jama. 2017;317:1110.

21. Griggs RC, Miller JP, Greenberg CR, Fehlings DL, Pestronk A, Mendell JR, et al. Efficacy and safety of deflazacort vs prednisone and placebo for Duchenne muscular dystrophy. Neurology. 2016;87:2123-31.

22. Shieh PB, McIntosh J, Jin F, Souza M, Elfring G, Narayanan S, et al. Deflazacort versus prednisone/prednisolone for maintaining motor function and delaying loss of ambulation: a post HOC analysis from the ACT DMD trial. Muscle Nerve. 2018:58:639-45.

23. Guglieri M, Bushby K, McDermott MP, Hart KA, Tawil R, Martens WB, et al. Developing standardized corticosteroid treatment for Duchenne muscular dystrophy. Contemp Clin Trials. 2017;58:34-9.

24. Griggs RC, Herr BE, Reha A, Elfring G, Atkinson L, Cwik V, et al. Corticosteroids in Duchenne muscular dystrophy: major variations in practice. Muscle Nerve. 2013:48:27-31.

25. Rangel V, Martin AS, Peay HL. DuchenneConnect registry report. PLoS Curr. 2012;:RRN1309.

26. Matthews E, Brassington R, Kuntzer T, Jichi F, Manzur AY. Corticosteroids for the treatment of Duchenne muscular dystrophy. Cochrane Database Syst Rev. 2016:Cd003725.

27. Kinnett K, Noritz G. The PJ Nicholoff steroid protocol for Duchenne and Becker muscular dystrophy and adrenal suppression. PLoS Curr. 2017:9 https://doi.org/10.1371/currents.md.d18deef7dac96ed135e0dc8739917b6e.

28. Johnsen SD. Prednisone therapy in Becker's muscular dystrophy. J Child Neurol. 2001;16:870-1.

29. Nakamura M, Sunagawa O, Hokama R, Tsuchiya H, Miyara T, Taba Y, et al. A Case of refractory heart failure in Becker muscular dystrophy improved with corticosteroid therapy. Int Heart J. 2016;57:640-4.

30. Biggar WD, Harris VA, Eliasoph L, Alman B. Long-term benefits of deflazacort treatment for boys with Duchenne muscular dystrophy in their second decade. Neuromuscul Disord. 2006;16:249-55.

31. King WM, Ruttencutter R, Nagaraja HN, Matkovic V, Landoll J, Hoyle C, et al. Orthopedic outcomes of long-term daily corticosteroid treatment in Duchenne muscular dystrophy. Neurology. 2007;68:1607-13.

32. Fox DJ, Kumar A, West NA, DiRienzo AG, James KA, Oleszek J. Trends with corticosteroid use in males with Duchenne muscular dystrophy born 1982-2001. J Child Neurol. 2015;30:21-6

33. McDonald CM, Henricson EK, Abresch RT, Han JJ, Escolar DM, Florence JM, et al. The cooperative international neuromuscular research group Duchenne natural history study-a longitudinal investigation in the era of glucocorticoid therapy: design of protocol and the methods used. Muscle Nerve. 2013:48:32-54

Ready to submit your research? Choose BMC and benefit from:

- fast, convenient online submission

- thorough peer review by experienced researchers in your field

- rapid publication on acceptance

- support for research data, including large and complex data types

- gold Open Access which fosters wider collaboration and increased citations

- maximum visibility for your research: over $100 \mathrm{M}$ website views per year

At BMC, research is always in progress.

Learn more biomedcentral.com/submissions 